\title{
Measuring farmers' preferences for weather index insurance in the Ayeyarwady Delta, Myanmar: a discrete choice experiment approach
}

\author{
Hideo Aizaki ${ }^{1}\left[\right.$ ] Jun Furuya ${ }^{2} \cdot$ Takeshi Sakurai $^{3} \cdot$ Swe Swe Mar $^{4}$
}

Received: 16 July 2020 / Revised: 13 December 2020 / Accepted: 19 December 2020 / Published online: 9 March 2021

(C) The Author(s) 2021

\begin{abstract}
This study examines farmers' preferences for weather index insurance (WII) in the Ayeyarwady Delta, Myanmar, using discrete choice experiments. It employs data taken from a survey of 317 rice farmers in the district of Labutta in the Ayeyarwady Region, which was conducted in March 2019. After being informed about WII and the trigger conditions, farmers were asked to answer discrete choice questions on WII packages. The hypothetical WII packages consisted of three attributes: the types of disaster that the insurance covers, the insurance coverage rate, and the annual insurance premium rate. A random parameter logit model analysis of the responses reveals that farmers prefer the WII packages covering cyclones, floods, and droughts to that for salt damage. The probabilities of selecting 64 hypothetical WII packages calculated from the estimates indicate that more than $50 \%$ of farmers can be expected to purchase seven WII packages for cyclones, floods, and droughts.
\end{abstract}

Keywords Discrete choice experiments · Random parameter logit · Stated preference $\cdot$ Weather index insurance · Myanmar · Ayeyarwady delta

\section{Introduction}

Global climate change may have significant negative impacts on farm management. In this regard, crop insurance could mitigate the raised weather-related risk, as farmers who purchase insurance will receive a payout from their provider if their yields decrease due to any natural disaster specified in the insurance contract. However, various issues arise when establishing crop insurance markets in developing countries (Mahul and Stutley 2010; Miranda and Farrin 2012; Jensen and Barrett 2017). For example, when deciding upon

Hideo Aizaki

azk-r@spa.nifty.com

1 Research Faculty of Agriculture, Hokkaido University, Sapporo, Hokkaido 060-8589, Japan

2 Social Sciences Division, Japan International Research Center for Agricultural Sciences, Tsukuba, Ibaraki 305-8686, Japan

3 Graduate School of Agricultural and Life Sciences, The University of Tokyo, Bunkyo, Tokyo 113-8657, Japan

4 Department of Soil and Water Science, Yezin Agricultural University, Yezin, Nay Pyi Taw, Myanmar the payout for each farmer, the provider must investigate the damage caused by the disaster and estimate the extent of crop loss. In developing countries, this task could take longer and cost more because of poor infrastructure (i.e., high transaction cost). Additionally, farmers who have purchased crop insurance may reduce their efforts to increase yields, as the insurance company cannot effectively monitor farmers' laziness and their low yields become compensated by insurance payouts (i.e., moral hazard). If the insurance payout depends on the extent of crop damage, high transaction cost and moral hazard will increase the price of insurance and hence the crop insurance market will not be established without government subsidies.

The weather index insurance (WII) is thought to reduce inherent inefficiencies in crop insurance within developing countries (Collier et al. 2009). First, WII can reduce transaction cost because farmers who purchase WII in advance will receive an insurance payout regardless of the extent of their crop loss whenever the weather in their area meets predefined, measurable trigger conditions (e.g., monthly rainfall throughout a dry season being less than $50 \mathrm{~mm}$ ). Companies can observe the weather in rural areas from remote locations using meteorological equipment. Second, WII can avoid moral hazard because farmers cannot control 
trigger conditions. Consequently, although the preparation of WII systems is costly, programs (or feasibility tests) have been operating in a number of developing countries, including Mexico, India, Ethiopia, and Thailand (see Barnett and Mahul 2007; Greatrex et al. 2015). To design a WII system for a given area, various conditions such as availability of weather information regarding the trigger, potential demand for WII, and local suppliers of WII must be assessed, and infrastructure, organizations, and other requirements for fulfilling these conditions are enhanced or constructed if necessary (International Fund for Agricultural Development 2011; World Bank 2011). Among these conditions, considering trigger conditions such as weather event and trigger level is vital. Trigger conditions for WII systems in practical use are set on the basis of rainfalls. This is because rainfall is good for the trigger conditions for WII: rainfall can be relatively and easily measured; an expected probability of meeting a trigger condition can be calculated well for a rainfall-based WII; and a relationship between the index (i.e., rainfall) and the extent of crop loss is understandable for both an insurance provider and farmers. The Government of Myanmar has recently been considering the introduction of WII. At present, a WII for the central arid region of Myanmar has been developed (SOMPO Holdings 2019) that uses rainfall as a trigger condition, while other areas, such as the Ayeyarwady Delta, remain without WII services. This is despite the fact that the Ayeyarwady Delta is a major producing area for rice (Ministry of Agriculture and Irrigation 2015) that is exposed to climate change effects because of its proximity to the sea and low elevation. However, designing a WII system with the trigger condition based on a cyclone or storm surge caused by climate change is a challenging task: unlike information regarding rainfall, climate change information is limited. Developing a suitable index for WII based on climate change is a natural scientific issue, whereas considering whether farmers demand such a WII is an economic issue.

To contribute toward an examination of the demand-side conditions of a feasible WII service for rice farmers in the Ayeyarwady Delta, this study measures farmers' preferences regarding the characteristics of a potential WII system using discrete choice experiments (DCEs), and then predicts farmers' probabilities of selecting various WII packages. ${ }^{1}$ The DCE approach (Louviere et al. 2000) is a stated preference method, in which peoples' preferences for goods and services (or their characteristics) are measured through the statistical analysis of responses to hypothetical discrete choice questions. Stated preference methods, including contingent

\footnotetext{
${ }^{1}$ Other papers in the special issue may examine relationships between socio-economic conditions of farmers and their evaluation of WII.
}

valuation (CV) (Carson 2012), have been popular in agroenvironmental valuation studies (e.g., Aizaki et al. 2006; Chiueh and Chen 2008; Maruyama and Takimoto 2008; Chen et al. 2018; Oishi et al. 2019); furthermore, they have also been applied in other fields, such as in the analysis of farmers' decisions regarding the introduction of new technologies (e.g., Cooper 1997; Kunimitsu 2009; Hong et al. 2017; Zuo et al. 2020; McGurk et al. 2020). DCEs are particularly appropriate for analyzing the decision-making of farmers because many conditions that could affect decisions can be considered. For example, Rigby et al. (2010) analyze horticultural producers' preferences for irrigation water contract conditions, such as the amount of guaranteed water and the probability of additional water, and Lutta et al. (2020) examine pastoralists' preferences for grazing management conditions, such as water availability and forage production (see, e.g., Bennett and Birol 2010 for more applications). Therefore, the DCE approach is suitable for our research. In fact, DCEs and CVs have been used to measure farmers' preferences or demands for WII in developing countries, including Bangladesh (Akter et al. 2016, 2017), Ethiopia (McIntosh et al. 2013; Castellani et al. 2014; Tadesse et al. 2017), Ghana (Adjabui et al. 2019), India (Ward and Makhija 2018), and Kenya (Sibiko et al. 2018). ${ }^{2}$ Previous studies have focused on a drought-based WII system for rice production in an area of India (Ward and Makhija 2018) and an inundation- and (hail or wind) storm-based WII system for maize production in a coastal area of Bangladesh (Akter et al. 2016, 2017); however, farmers' preferences for these WII systems may not be suitable for the Ayeyarwady Delta area of Myanmar, where natural disasters such as saltwater and cyclone have affected farming. To the best of our knowledge, the only previous study that focused on farmers in the Ayeyarwady Delta area of Myanmar was conducted by $\mathrm{Gu}$ (2018), which reports the results of preliminary DCE questions gathered as part of the baseline survey for the project. The WII system designed in this study could help with the consideration of a WII system in other countries that are similar to those of the Ayeyarwady Delta area of Myanmar. For the entire project's details, refer to the editorial of the special issue.

\footnotetext{
2 Among these studies, McIntosh et al. (2013) and Adjabui et al. (2019) use CV, while Castellani et al. (2014), Akter et al. (2016, 2017), Tadesse et al. (2017), Sibiko et al. (2018), and Ward and Makhija (2018) use DCEs. Stated preference methods have also been applied in various non-agricultural insurance studies. For example, Wakamatsu et al. (2019) measure preferences for micro health insurance, while Geweke (2012) conducts a DCE analysis of automobile insurance. See Jaspersen (2016) for more applications.
} 


\section{Methods and data}

\section{Outline of the survey}

The survey was designed following the results of the preliminary DCE questions for WII (Gu 2018), the supplementary survey conducted the year before our survey, and experience drawn from another WII research project applying an experimental approach to farmers in Zambia (Miura and Sakurai 2012). The survey was conducted by (1) using visual aids to explain to farmers the concept of insurance and the characteristics of WII, including trigger conditions assumed for our study, (2) providing options in DCE questions using words and visual aids, and (3) asking warm-up questions to improve the farmers' understanding of WII. Survey materials, including questions and explanations, were developed in English and then translated into Burmese. The survey method is explained below.

Labutta District in the Ayeyarwady Region was chosen as our study site because it is one of the districts that are regularly affected by saline water intrusion in the region and the district was most heavily damaged by Cyclone Nargis in 2008 (Food and Agriculture Organization of the United Nations 2009). We selected a total of ten village tracts (hereafter we simply call them villages) that are facing the Thet Ke Thaung River, a branch of the Ayeyarwady River, and are contiguously located from the mouth of the Yway River. In each village, 32 rice-producing farm households were randomly chosen from the register of land-owning households provided by the village administration. As a result, we had a total of 320 sample households. ${ }^{3}$

The DCE for WII was conducted with the sample households in March 2019. Our enumeration team visited one or two villages per day. In each village, respondents from sample households were gathered at a location such as a temple, a village meeting place, or a village leader's house. They were then divided into four or five groups of five to eight farmers, and group sessions were conducted. A session consisted of four steps: (1) explaining insurance and WII with the aid of a poster; (2) asking warm-up questions; (3) explaining hypothetical WII arrangements, including the trigger conditions; and (4) asking questions about the hypothetical WII packages. The first step was undertaken by the leader of the enumerator team, and the remaining three steps were conducted person-to-person: an enumerator faced a farmer. After completing interviews in the 10 villages, we obtained 317 valid responses out of 320 , as three farmers were absent.

\footnotetext{
${ }^{3}$ Please refer to the editorial for details on the sample villages and farm households.
}

\section{The design of hypothetical WII services}

The hypothetical WII packages in the DCE questions are as follows. An insurance company will sell various types of WII packages for rice farming in the next crop season, with packages specifying three characteristics: the types of disaster that the insurance covers, including cyclone, flood, drought, and salt damage; the insurance coverage rate, which is defined by the share of the expected normal rice yield, set at four levels of $100 \%, 80 \%, 60 \%$, and $40 \%$; and the annual insurance premium rate, which is also defined by the share of the expected normal rice yield and set at four levels of $1 / 100,4 / 100,8 / 100$, and 12/100. Different combinations of these three characteristics produce different WII packages. Furthermore, we assume that insurance money will be paid when each disaster type fulfills the following trigger conditions: for cyclone-based WII, the issuance of a cyclone warning by the Government of Myanmar and the sea level at Haing Gyi Kyun exceeding four meters; for flood-based WII, the water level of the Thet Ke Thaung exceeding $3.5 \mathrm{~m}$ or the monthly rainfall in Labutta exceeding $1000 \mathrm{~mm}$ in August; for drought-based WII, the rainfall in Labutta being below $400 \mathrm{~mm}$ over August; and for salt damage-based WII, the salinity level of Thet Ke Thaung exceeding one part per thousand. These trigger conditions were decided through discussions with research project team members, including researchers in the fields of economics, remote sensing, and soil and water sciences.

After explaining the characteristics of the hypothetical WII packages, the respondents were asked to answer DCE questions in a binary choice format. Respondents were asked to classify 16 WII profiles, which were presented on paper cards (Fig. 1), into two groups: ones they would like to purchase and ones they would not. The 16 profiles were created using an orthogonal array with four four-level factors. The efficiency-based design approach has become popular in applied DCE studies (e.g., Scarpa and Rose 2008; Rose and Bliemer 2009), alongside the orthogonal array-based design approach (e.g., Franzén et al. 2016; Perni and Martínez-Paz. 2017; Just et al. 2018; Kikushima et al. 2018; Rakatama et al. 2018; Wu et al. 2020). Although the efficiency-based approach usually enables the generation of statistically highly efficient choice sets, it may also generate inefficient choice sets if preconditions are mis-specified (Walker et al. 2018). This means that the efficiency-based approach has no absolute advantage over other design approaches. While this binary choice format may be rare in some research fields, it has been applied: for example, Louviere and Islam (2008) use binary DCEs, in which profiles are designed with an orthogonal array. Aizaki et al. (2014) review three types of binary choice format in DCEs (see also Rao 2014). The format aided the ability of respondents to answer questions: with each profile presented on a physical card, the 


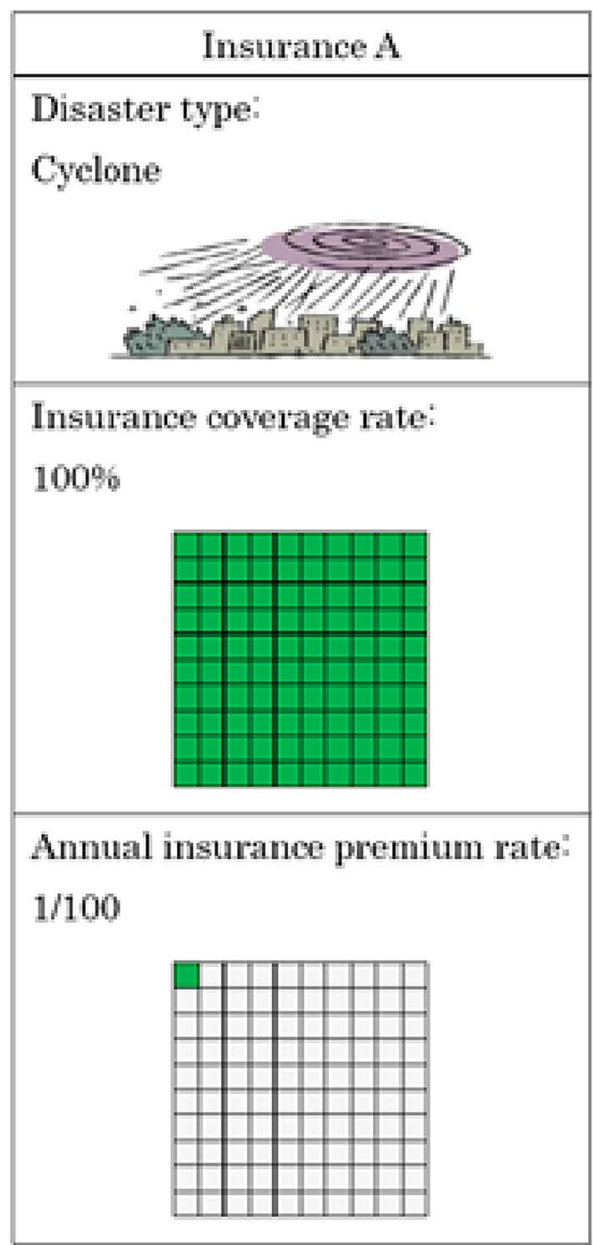

Fig. 1 An example profile for discrete choice experiment questions

respondents could easily compare profiles and make decisions by trial and error while considering the entire profiles.

After dividing the profiles into two groups, the respondents were also asked to rank the profiles they would like to purchase according to their preference, with the intention of providing more information about farmer preferences for WII packages. However, this also imposed the psychological burdens of ranking profiles on the respondents. Comparing the results from the binary analysis of the responses and those from the ranking analysis is a further issue to be discussed.

The survey also asked respondents to answer DCE questions in a multinomial choice format before the binary choice format questions (see the "Appendix" for more details), but these results are not used in this paper. This is because the value of the goodness of fit measure (i.e., the adjusted McFadden's $\mathrm{R}^{2}$ ) for a conditional logit model analysis of the responses in multinomial choice format is 0.062 (see Table 5), which is less than that of the binary logit model analysis of responses in the binary choice format (see Table 2) under the same utility function (see the next subsection for details on our models). Even when a random parameter logit model is used to analyze the responses to binary and multinomial DCE questions, the binary DCE model is superior to the multinomial DCE model (see Tables 2 and 5). These two formats are used because the pre-test conducted the year before the survey highlighted that some respondents were having difficulty answering DCE questions in a multinomial choice format. As a result, we adopted an easier format of DCE questioning. However, since we had no advance knowledge of which format would be more appropriate for the study, conducting both was a necessary exercise even though we faced the risk of causing the respondents greater psychological stress by asking more questions.

\section{Specification of empirical discrete choice models}

Responses to DCE questions can be analyzed using discrete choice models, which are based on the random utility theory (Train 2009). The theory assumes that individuals (e.g., farmers in this study) select an alternative in a choice set according to their utility of the alternatives included in the set. The utility of alternative $i$ for farmer $n\left(U_{i n}\right)$ consists of a systematic component $\left(V_{i n}\right)$ and a stochastic component $\left(\varepsilon_{i n}\right)$, as follows:

$U_{i n}=V_{\text {in }}+\varepsilon_{\text {in }}$

$V_{\text {in }}=x_{i n}^{\prime} \beta$

where $x$ is a vector of independent variables and $\beta$ is a vector of the coefficients.

Various discrete choice models can be derived from the utility function, following assumptions regarding the systematic and stochastic components. The fundamental model is a binary logit (BL) model, where the stochastic components are independently and identically distributed type I extreme value. Following the BL model, the probability of farmer $n$ selecting alternative $i$ as one they would like to purchase is expressed as follows:

$P_{n}(i)=\frac{e^{V_{i n}}}{e^{V_{i n}}+1}$

where the systematic component of the utility for alternative $i$ that farmer $n$ would not like to purchase is normalized to 0 . The above model assumes that coefficients are the same for all farmers (i.e., we assume homogenous preferences). Although our objective is to examine farmers' preferences for WII packages, farmers' characteristics 
that affect their behavior are not included within the scope of the study. However, the homogeneity assumption may affect the accuracy of the analysis. Furthermore, the extent of heterogeneity in preference for WII is important for considering the potential demand for a WII package. A farmers' subjective probability of suffering from a disaster is likely to affect their preference for the disaster covered by the WII package. Therefore, a distribution of estimated coefficients for the disasters covered by WII packages allows for the indirect presumption of how widely and to what extent the disasters could affect farmers in a given area. Therefore, we also apply a random parameter logit (RPL) model (see, e.g., Hensher and Greene 2003; Train 2009), which assumes that coefficients for independent variables can differ among individuals.

The systematic component of the utility of a hypothetical WII (profile) $i$ for farmer $n$ is assumed to be given as follows:

$$
\begin{aligned}
V_{i n}= & \beta_{0}+\beta_{1} \text { CYCLONE }_{i n}+\beta_{2} \text { FLOOD }_{i n}+\beta_{3} \text { DROUGHT }_{i n} \\
& +\beta_{4} \text { COVERAGE }_{i n}+\beta_{5} \text { PREMIUM }_{i n}
\end{aligned}
$$

where CYCLONE $i$ is an effect-coded variable taking the value of 1 if package $i$ is designed for cyclones, -1 for salt damage, and 0 otherwise; $\mathrm{FLOOD}_{i}$ is an effect-coded variable taking the value of 1 if package $i$ is designed for floods, -1 for salt damage, and 0 otherwise; DROUGHT $_{i}$ is an effect-coded variable taking the value of 1 if package $i$ is designed for droughts, -1 for salt damage, and 0 otherwise; COVERAGE $_{i}$ is the insurance coverage rate of package $i$ (with a range from 0.4 to 1.0 according to the definition of the coverage attribute); PREMIUM $_{i}$ is an annual insurance premium rate of package $i$ (with a range from 0.01 to 0.12 according to the definition of the premium attribute); $\beta_{0}$ is a constant; and $\beta$ s are coefficients to be estimated. The dummy coding scheme, where the coefficient (utility weight) for the base level of a qualitative attribute is set to zero, enables us to easily interpret the coefficients for the remaining levels of the attribute. However, the dummy coding results in the coefficient for the base level being confounded with a constant in the utility function. An advantage of using the effect coding scheme is that a unique coefficient for the base level (i.e., salt damage in our models) can be calculated, and thus, the coefficients can be compared among all levels of an attribute (e.g., Hollin et al. 2015). In the model specification mentioned above, the coefficient corresponding to the salt damage is the negative sum of the coefficients for the remaining three effect-coded variables: $-\left(\beta_{1}+\beta_{2}+\beta_{3}\right)$ (see Beck and Gyrd-Hansen 2005 and Hensher et al. 2015 for details on the dummy and effect coding schemes). This feature of the effect coding scheme functions well, especially for the RPL model. This is because the RPL model allows us to calculate individual-specific coefficients (Train 2009), and thus, we can view heterogeneity in preferences for the four disasters covered by WII in the sample.

For the RPL model, we assume that coefficients for the three disaster type attribute variables $\left(\beta_{1}, \beta_{2}\right.$, and $\left.\beta_{3}\right)$ follow normal distributions with mean $\beta_{j 0}$ and standard deviation $\sigma_{j}$, respectively (where $j=1,2,3$ ):

$\beta_{j n}=\beta_{j 0}+\sigma_{j} \eta_{j n}$,

where $\eta_{j n}$ follows a standard normal distribution. Furthermore, we assume that the coefficient for COVERAGE $\left(\beta_{4}\right)$ varies according to a lognormal distribution with the parameters $\beta_{40}$ and $\sigma_{4}$ and that for PREMIUM $\left(\beta_{5}\right)$ varies according to a negative lognormal distribution with the parameters $\beta_{50}$ and $\sigma_{5}$ (Train 2009; Holmes et al. 2017):

$\beta_{4 n}=\exp \left(\beta_{40}+\sigma_{4} \eta_{4 n}\right)$,

$\beta_{5 n}=-\exp \left(\beta_{50}+\sigma_{5} \eta_{5 n}\right)$

The lognormal distribution assumption requires that the coefficient for coverage rate $\left(\beta_{4 n}\right)$ is positive for all farmers, while the negative lognormal distribution assumption (i.e., the exponential function is multiplied by -1 in Eq. (7)) holds the coefficient for the premium rate $\left(\beta_{5 n}\right)$ negative for all farmers. These assumptions are reasonable because rational farmers prefer higher coverage rates that payout higher amounts and, ceteris paribus, they also prefer low premium rates that decrease their payments for insurance packages. Note that the RPL model estimates $\beta_{j 0}$ and $\sigma_{j}$, while individual-specific coefficients $\beta_{j n}$ are calculated from the estimates.

\section{Software for the design and analysis}

For our study, we used R (R Core Team 2020) and its addin packages. The support.CEs (Aizaki 2012, 2016; Aizaki et al. 2014) and DoE.base (Grömping 2018) packages were used for designing choice sets and preparing the dataset for the study. The apollo (Hess and Palma 2019, 2020) package was used for the model estimations and the post-estimation calculations, such as predicting choice probabilities of WII packages. A maximum likelihood estimation procedure is used to fit the BL model, while a simulated maximum likelihood estimation procedure with 500 Halton draws is used to fit the RPL model.

\section{Results and discussion}

Table 1 shows the number of farmers who correctly understand the principles of insurance and WII. As a warm-up question, farmers were asked to select correct descriptions 
Table 1 Percentages of respondents selecting correct statements

Insurance is a way of helping one another when a problem occurs

Insurance companies pay the people who have purchased an insurance package and who face a predefined problem

People who need protection from a specific problem pay an insurance premium to an insurance company in advance

Farmers who need weather index insurance for a specific natural disaster pay an insurance premium to an insurance company before sowing crops

Farmers who have purchased the weather index insurance will receive insurance money regardless of the extent of crop loss if a predefined natural disaster affects the village they live in

Farmers who have not purchased the weather index insurance will not receive insurance money, even if they live in the village where 79 the predefined natural disaster has struck and, consequently, damaged their crops

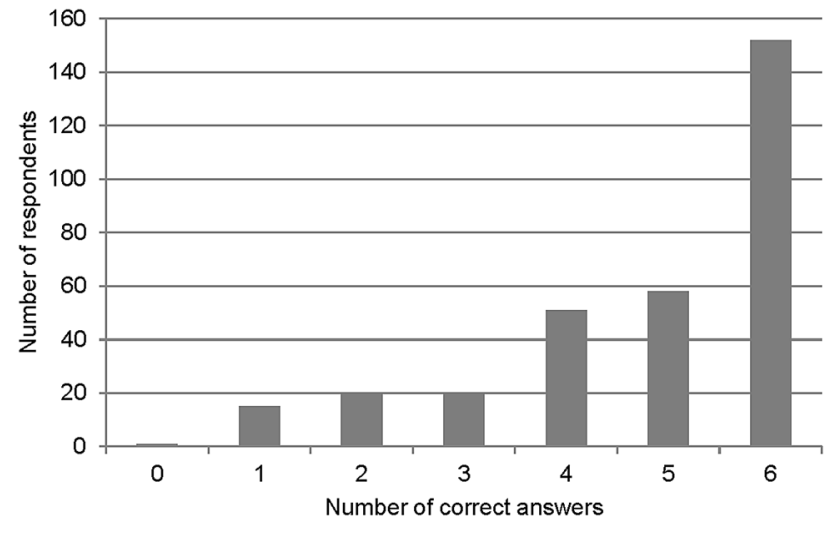

Fig. 2 Respondents' understanding of insurance and WII

from six statements regarding both insurance and WII. Approximately $80 \%$ of farmers correctly categorized the statements, suggesting that farmers developed a good understanding of WII through our explanation in the first step of the survey session. Unfortunately, the extent of overall understanding was lower, as approximately $50 \%$ of respondents answered every question correctly while approximately $20 \%$ of respondents scored $50 \%$ or less (Fig. 2). ${ }^{4}$ All farmers were informed of the correct answers after the questioning.

Table 2 indicates the BL and RPL model estimation results. A goodness of fit measure (adjusted McFadden's $\mathrm{R}^{2}$ ) reveals that the RPL model is superior to the BL model. Accordingly, we focus only on the RPL estimates. The P values show that all the parameters are significantly different from zero, at $5 \%$ or less. Although the mean for the annual insurance premium rate variable (PREMIUM) $\left(\beta_{50}\right)$ has a positive value, this means that WII packages with

\footnotetext{
${ }^{4}$ Respondents' characteristics such as their previous exposure to information regarding WII or their education levels may affect their correct response rates.
}

lower premium rates are preferred because the coefficient $\left(\beta_{5 n}\right)$ is assumed to follow a negative lognormal distribution (see Eq. (7)). The positive mean for the insurance coverage rate variable (COVERAGE) reveals that WII packages with higher coverage rates are preferred. The significantly positive standard deviations for PREMIUM and COVERAGE suggest that the coefficients of the two variables differ among farmers. The positive mean for three effectcoded disaster type variables (CYCLONE, FLOOD, and DROUGHT) show that cyclone-, flood-, and drought-based WII packages are preferred to salt damage-based ones, on average. The standard deviations for the three effect-coded variables are significantly positive, such that the preference orders of the four disaster types may differ among farmers. To display the heterogeneity of farmer preferences in disaster types, kernel density estimates (Hensher and Greene 2003) for the four disaster types are drawn from the RPL model results (Fig. 3). The variation in the preference for flood and drought is relatively small, whereas the variation for salt damage is relatively large. Furthermore, some farmers displayed a positive value for salt damage, meaning that they prefer a WII package for salt damage than for one or more of the remaining WII packages for cyclones, floods, and droughts, since the estimate for salt damage could be defined as a negative summation of those for the three effectcoded disaster type variables. Relatively large preference heterogeneity for salt damage suggests that the extent of salt damage varies among farmers: some farmers may incur no salt damage while others may incur large salt damage even under the same weather conditions, due to the differences in the location of their farmlands (e.g., distance from the mouth of the river).

To determine the share of farmers that prefer each disaster type, preference order of the four disaster types by farmer is estimated using individual farmers' estimates (Train 2009) for the three effect-coded disaster type variables (Table 3 ). Holding other conditions constant, 112 farmers (35\% of the total) ranked the drought as their first preference, while 85 
Table 2 Binary logit and random parameter logit model estimates

Fig. 3 Kernel density estimates for effect-coded variables of cyclone, flood, drought, and salt damage

\begin{tabular}{|c|c|c|c|c|c|c|}
\hline \multirow[t]{2}{*}{ Variable } & \multicolumn{3}{|c|}{ Binary logit (BL) } & \multicolumn{3}{|c|}{ Random parameter logit (RPL) } \\
\hline & Estimate & S.E. ${ }^{1}$ & $P$ value & Estimate $^{2}$ & S.E. ${ }^{1}$ & $P$ value \\
\hline \multicolumn{7}{|l|}{ Parameter (BL)/fixed parameter (RPL) } \\
\hline Constant & -1.1338 & 0.1191 & 0.000 & -1.4654 & 0.1995 & 0.000 \\
\hline \multicolumn{7}{|l|}{ Parameter (BL)/mean (RPL) } \\
\hline CYCLONE & 0.1540 & 0.0762 & 0.043 & 0.3693 & 0.1581 & 0.019 \\
\hline FLOOD & 0.1547 & 0.0656 & 0.018 & 0.4589 & 0.1303 & 0.000 \\
\hline DROUGHT & 0.2392 & 0.0712 & 0.001 & 0.5242 & 0.1409 & 0.000 \\
\hline COVERAGE & 1.4119 & 0.1438 & 0.000 & 0.8442 & 0.1183 & 0.000 \\
\hline PREMIUM & -15.6042 & 1.1953 & 0.000 & 3.5984 & 0.0930 & 0.000 \\
\hline \multicolumn{7}{|l|}{ Standard deviation (RPL) } \\
\hline CYCLONE & & & & 1.7631 & 0.2220 & 0.000 \\
\hline FLOOD & & & & 1.1736 & 0.2212 & 0.000 \\
\hline DROUGHT & & & & 1.4955 & 0.1902 & 0.000 \\
\hline COVERAGE & & & & 0.7448 & 0.0886 & 0.000 \\
\hline PREMIUM & & & & 1.4239 & 0.1683 & 0.000 \\
\hline \multicolumn{7}{|l|}{ Summary statistics } \\
\hline Number of respondents & & & 317 & & & 317 \\
\hline Number of observations & & & 5072 & & & 5072 \\
\hline Log-likelihood value at 0 & & & -3515.6 & & & -3515.6 \\
\hline Log-likelihood value at convergence & & & -2717.6 & & & -2238.3 \\
\hline Adjusted McFadden’s $\mathrm{R}^{2}$ & & & 0.225 & & & 0.360 \\
\hline
\end{tabular}

${ }^{1}$ S.E. stands for a robust standard error. ${ }^{2}$ Means and standard deviations for COVERAGE and those for PREMIUM refer to those of the underlying normal distribution, respectively (see the subsection "Specification of empirical discrete choice models.")
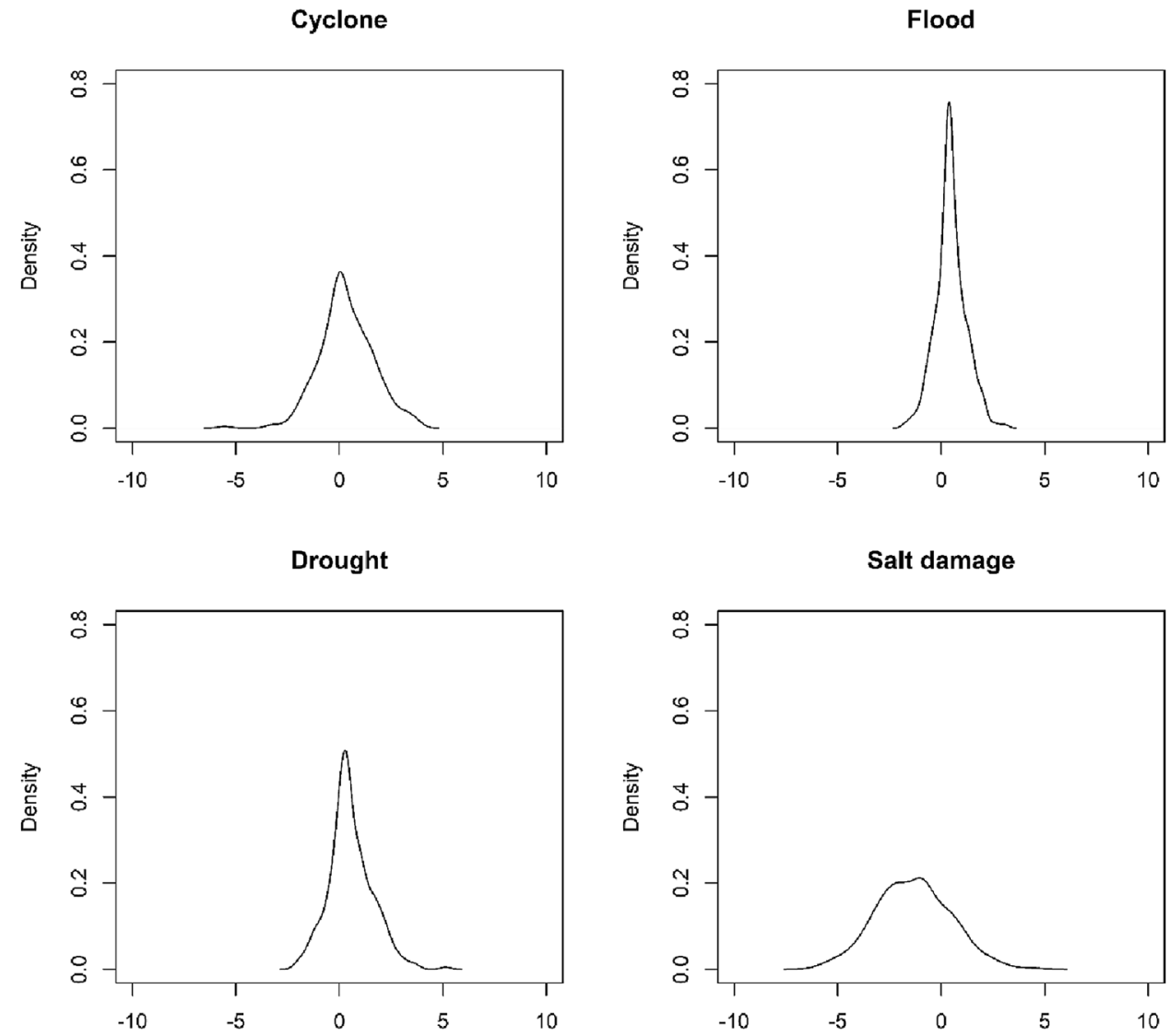
Table 3 Estimated preference order aggregation of four disaster types

\begin{tabular}{lcccc}
\hline & Cyclone & Flood & Drought & Salt damage \\
\hline First preference & $85(27)$ & $76(24)$ & $112(35)$ & $44(14)$ \\
Second preference & $51(16)$ & $146(46)$ & $96(30)$ & $24(8)$ \\
Third preference & $123(39)$ & $77(24)$ & $92(29)$ & $25(8)$ \\
Fourth preference & $58(18)$ & $18(6)$ & $17(5)$ & $224(71)$ \\
Total & $317(100)$ & $317(100)$ & $317(100)$ & $317(100)$ \\
\hline
\end{tabular}

Unit: Numbers of respondents and percentages in parentheses

(27\%), 76 (24\%), and 44 (14\%) farmers ranked the cyclone, flood, and salt damage as their first preference, respectively. On the other hand, 224 farmers $(71 \%)$ ranked salt damage as their least preferred condition, while $58(18 \%), 18(6 \%)$, and 17 (5\%) farmers ranked the cyclone, flood, and drought as their least preferred.

Table 4 shows the predictions of farmers' demands for the 64 WII packages (made up of the combination of the four disaster types, the four coverage rates, and the four premium rates) calculated from the estimates. Each cell denotes the mean probability of 317 farmers selecting a particular WII package. For example, the probability that the farmers would purchase a cyclone-based WII package with a coverage rate of $40 \%$ and a premium rate of $1 \%$ is 0.404 , meaning that $40.4 \%$ of farmers can be expected to purchase this WII package if only this package was made available. The calculated choice probabilities reveal that the seven WII packages with simulated probabilities of 0.5 or more are cyclone-, flood-, and droughtbased, while there are no such packages for salt damage. Farmers' median willingness-to-pay (WTP) values for the former seven packages can be calculated. The median WTP for a WII package is defined as the value of a premium rate for the WII package at which the probability of selecting it as a prospective purchase is exactly equal to 0.5 . Accordingly, the median WTP values for cyclone-based WII packages with coverage rates of $80 \%$ and $100 \%$ are $1.6 \%$ and $2.6 \%$, respectively. For floodbased WII packages with coverage rates of $80 \%$ and $100 \%$, the median WTP values are $1.8 \%$ and $2.8 \%$, respectively. For drought-based WII packages with coverage rates of $60 \%, 80 \%$, and $100 \%$, the median WTP values are $1.0 \%, 1.9 \%$, and $2.9 \%$, respectively.

\section{Concluding remarks}

This study examines farmers' preferences for WII among rice farmers in the Ayeyarwady Delta area of Myanmar using DCEs. The results indicate that heterogeneity in preference for salt damage is larger than those for cyclone, floods, and droughts and that more farmers prefer WII packages to cover themselves against cyclones, floods, and droughts than those to hedge against salt damage. This suggests that salt damage occurs as a local-specific disaster (i.e., the extent of salt damage varies among farmers in this area), while the remaining three disasters widely and equally affect farmers in this area. Thus, WII for salt damage might not be suitable for this area. However, if an equipment that can measure detailed salinity in water is put to practical use in this area, it could possibly make the WII for salt damage feasible in this area. On the other hand, WIIs for the remaining three disasters might be appropriate for this area. Although additional information is needed to design actual WII packages that are suitable for farmers in the area, these results could assist the Government of Myanmar and other organizations in this task, since the relationship between the quantity of WII packages demanded and the premium rate is vital for designing effective products and developing sales strategies.

A major limitation of this study must be noted when considering the results: our method of informing farmers about WII. On the basis of preliminary surveys, we designed features of the hypothetical WII-including the trigger conditions - and then explained these through a poster and handouts with illustrations. These explanations could be further improved. For example, some technical terms could be modified, as these may reduce farmers' understanding of WII, and thus might affect their preferences in future WII packages. The second limitation is that farmers' characteristics are not introduced explicitly into the analysis, although

Table 4 Simulated probabilities of selecting WII packages by disaster type, coverage rate, and premium rate. Bold values indicate simulated probabilities of 0.5 or more

\begin{tabular}{|c|c|c|c|c|c|c|c|c|c|c|c|c|c|c|c|c|}
\hline \multirow[b]{3}{*}{ Premium } & \multirow{2}{*}{\multicolumn{4}{|c|}{$\begin{array}{l}\text { Disaster type: cyclone } \\
\text { Coverage }\end{array}$}} & \multirow{2}{*}{\multicolumn{4}{|c|}{$\begin{array}{l}\text { Disaster type: flood } \\
\text { Coverage }\end{array}$}} & \multirow{2}{*}{\multicolumn{4}{|c|}{$\begin{array}{l}\text { Disaster type: drought } \\
\text { Coverage }\end{array}$}} & \multirow{2}{*}{\multicolumn{4}{|c|}{$\begin{array}{l}\text { Disaster type: salt damage } \\
\text { Coverage }\end{array}$}} \\
\hline & & & & & & & & & & & & & & & & \\
\hline & $40 \%$ & $60 \%$ & $80 \%$ & $100 \%$ & $40 \%$ & $60 \%$ & $80 \%$ & $100 \%$ & $40 \%$ & $60 \%$ & $80 \%$ & $100 \%$ & $40 \%$ & $60 \%$ & $80 \%$ & $100 \%$ \\
\hline $1 \%$ & 404 & 0.480 & .546 & 0.603 & 405 & 0.4 & 0.563 & & 21 & 0.501 & 0.5 & 0.6 & 0.241 & 0.302 & 0.361 & 0.417 \\
\hline $4 \%$ & 0.265 & 0.327 & 0.385 & 0.438 & 0.257 & 0.326 & 0.390 & 0.446 & 0.273 & 0.339 & 0.399 & 0.454 & 0.157 & 0.203 & 0.251 & 0.298 \\
\hline $8 \%$ & 0.184 & 0.234 & 0.282 & 0.328 & 0.175 & 0.230 & 0.282 & 0.331 & 0.189 & 0.241 & 0.292 & 0.338 & 0.109 & 0.145 & 0.183 & 0.221 \\
\hline $12 \%$ & 0.141 & 0.182 & 0.223 & 0.263 & 0.132 & 0.177 & 0.221 & 0.263 & 0.144 & 0.187 & 0.230 & 0.271 & 0.083 & 0.112 & 0.144 & 0.177 \\
\hline
\end{tabular}


we considered the heterogeneity in farmer preferences for WII attributes using the RPL model. To extract detailed information from the estimated models, farmers' characteristics should be set as independent variables, shifting the means of random parameters in the RPL model. The last limitation of this study is that insurance providers were not considered: economic conditions of supplying WII are also vital to design WII suitable for this area. Further studies are needed to overcome these limitations.

\section{Appendix}

For the DCE questions in a multinomial choice format, farmers were asked to select one package that they would like to purchase from three alternatives: two hypothetical WII packages (profiles) and an opt-out (none of these) option. A profile consists of three attributes that are the same as those used in the DCE questions under a binary choice format. The format of a profile is the same as that in the binary choice format (see Fig. 1). This style of questioning is repeated four times per respondent, while changing the profiles shown. A total of 32 choice sets were generated using a rotation design approach (Chrzan and Orme 2000; Johnson et al. 2007). These were then divided randomly into eight versions (i.e., four DCE questions for each of eight versions).

Table 5 shows the conditional logit and random parameter logit model estimates of the responses to DCE questions in a multinomial choice format, where the model specifications follow that of the binary choice format: the systematic component of the utility for WII packages is also the same as that of the binary choice format; the systematic component of the utility for the opt-out option is normalized to 0 ; and independent variables are defined in the same manner as in the binary choice format.
Table 5 Conditional logit and random parameter logit model estimates of the responses to multinomial discrete choice experiment questions

\begin{tabular}{|c|c|c|c|c|c|c|}
\hline \multirow[t]{2}{*}{ Variable } & \multicolumn{3}{|c|}{ Conditional logit (CL) } & \multicolumn{3}{|c|}{ Random parameter logit (RPL) } \\
\hline & Estimate & S.E. ${ }^{2}$ & $P$ value & Estimate $^{3}$ & S.E. ${ }^{2}$ & $P$ value \\
\hline \multicolumn{7}{|l|}{ Parameter (CL)/fixed parameter (RPL) } \\
\hline $\mathrm{ASC}^{1}$ & -0.1905 & 0.1839 & 0.300 & 0.0884 & 0.3370 & 0.793 \\
\hline \multicolumn{7}{|l|}{ Parameter (CL)/mean (RPL) } \\
\hline CYCLONE & 0.1695 & 0.0790 & 0.032 & 0.4293 & 0.1813 & 0.018 \\
\hline FLOOD & 0.2604 & 0.0678 & 0.000 & 0.6970 & 0.1449 & 0.000 \\
\hline DROUGHT & 0.1721 & 0.0766 & 0.025 & 0.4442 & 0.1597 & 0.005 \\
\hline COVERAGE & 0.8786 & 0.1982 & 0.000 & 0.3686 & 0.2786 & 0.186 \\
\hline PREMIUM & -10.3556 & 1.1686 & 0.000 & 2.6469 & 0.2411 & 0.000 \\
\hline \multicolumn{7}{|l|}{ Standard deviation (RPL) } \\
\hline CYCLONE & & & & 1.7838 & 0.3463 & 0.000 \\
\hline FLOOD & & & & 0.7335 & 0.2981 & 0.014 \\
\hline DROUGHT & & & & 1.4530 & 0.3098 & 0.000 \\
\hline COVERAGE & & & & 0.8063 & 0.1209 & 0.000 \\
\hline PREMIUM & & & & 2.5141 & 0.2527 & 0.000 \\
\hline \multicolumn{7}{|l|}{ Summary statistics } \\
\hline Number of respondents & & & 317 & & & 317 \\
\hline Number of observations & & & 1268 & & & 1268 \\
\hline Log-likelihood value at 0 & & & -1393.0 & & & -1393.0 \\
\hline Log-likelihood value at convergence & & & -1301.1 & & & -1125.4 \\
\hline Adjusted McFadden's R ${ }^{2}$ & & & 0.062 & & & 0.184 \\
\hline
\end{tabular}

${ }^{1}$ ASC stands for an alternative specific constant, which is included in WII alternatives. ${ }^{2}$ S.E. stands for a robust standard error. ${ }^{3}$ Means and standard deviations for COVERAGE and those for PREMIUM refer to those of the underlying normal distribution, respectively (see the subsection "Specification of empirical discrete choice models.") 
Acknowledgements This work presents part of the results from the Japan International Research Center for Agricultural Sciences (JIRCAS) project on "Climate Change Measures in Agricultural Systems: Development of agricultural technologies for reducing greenhouse gas emissions and climate-related risks in developing countries (a subtheme: Designing weather index insurance of agricultural products to extreme events)." This work was partially supported by the Japan Society for the Promotion of Science (JSPS) KAKENHI Grant Numbers JP16K07886 and JP20K06251.

Open Access This article is licensed under a Creative Commons Attribution 4.0 International License, which permits use, sharing, adaptation, distribution and reproduction in any medium or format, as long as you give appropriate credit to the original author(s) and the source, provide a link to the Creative Commons licence, and indicate if changes were made. The images or other third party material in this article are included in the article's Creative Commons licence, unless indicated otherwise in a credit line to the material. If material is not included in the article's Creative Commons licence and your intended use is not permitted by statutory regulation or exceeds the permitted use, you will need to obtain permission directly from the copyright holder. To view a copy of this licence, visit http://creativecommons.org/licenses/by/4.0/.

\section{References}

Adjabui JA, Tozer PR, Gray DI (2019) Willingness to participate and pay for index-based crop insurance in Ghana. AgricFinanc Rev 79(4):491-507. https://doi.org/10.1108/AFR-01-2019-0001

Aizaki H (2012) Basic functions for supporting an implementation of choice experiments in R. J Stat Softw 50(C2):1-24. https://doi. org/10.18637/jss.v050.c02

Aizaki H (2016) support.CEs: basic functions for supporting an implementation of choice experiments. R package version $0.4-1$. https ://CRAN.R-project.org/package=support.CEs

Aizaki H, Nakatani T, Sato K (2014) Stated preference methods using R. Chapman and Hall/CRC Press, New York

Aizaki H, Sato K, Osari H (2006) Contingent valuation approach in measuring the multifunctionality of agriculture and rural areas in Japan. Paddy Water Environ 4:217-222. https://doi.org/10.1007/ s10333-006-0052-8

Akter S, Krupnik TJ, Khanam F (2017) Climate change skepticism and index versus standard crop insurance demand in coastal Bangladesh. Reg Environ Chang 17:2455-2466. https://doi.org/10.1007/ s10113-017-1174-9

Akter S, Krupnik TJ, Rossi F, Khanam F (2016) The influence of gender and product design on farmers' preferences for weatherindexed crop insurance. Glob Environ Chang 38:217-229. https ://doi.org/10.1016/j.gloenvcha.2016.03.010

Barnett B, Mahul O (2007) Weather index insurance for agriculture and rural areas in lower-income countries. Am J Agric Econ 89:1241-1247. https://doi.org/10.1111/j.1467-8276.2007.01091.x

Beck M, Gyrd-Hansen D (2005) Effects coding in discrete choice experiments. Health Econ 14:1079-1083. https://doi.org/10.1002/ hec. 984

Bennett J, Birol E (eds) (2010) Choice experiments in developing countries: implementation, challenges and policy implications. Edward Elgar, Cheltenham, UK. https://doi.org/10.4337/9781781000649

Carson RT (2012) Contingent valuation: a comprehensive bibliography and history. Edward Elgar, Northampton, MA

Castellani D, Viganò L, Tamre B (2014) A discrete choice analysis of smallholder farmers' preferences and willingness to pay for weather derivatives: evidence from Ethiopia. J Appl Bus Res 30:1671-1692. https://doi.org/10.19030/jabr.v30i6.8882

Chen B, Qiu Z, Usio N, Nakamura K (2018) Conservation and contingent valuation of farming landscape amenities by visitors: a case study of terraced paddy fields in Central Japan. Paddy Water Environ 16:561-570. https://doi.org/10.1007/s1033 3-018-0648-9

Chiueh YW, Chen MC (2008) Environmental multifunctionality of paddy fields in Taiwan: an application of contingent valuation method. Paddy Water Environ 6:229-236. https://doi.org/10.1007/ s10333-008-0110-5

Chrzan K, Orme B (2000) An overview and comparison of design strategies for choice-based conjoint analysis. In: Proceedings of the Sawtooth Software Conference. Sawtooth Software. 161-177. https://www.sawtoothsoftware.com/support/technical-papers/ conference-proceedings/proceedings2000/. Accessed 12 July 2020

Collier B, Skees J, Barnett B (2009) Weather index insurance and climate change: opportunities and challenges in lower income countries. The Geneva Pap Risk Insur Issues Pract 34:401-424. https ://doi.org/10.1057/gpp.2009.11

Cooper JC (1997) Combining actual and contingent behavior data to model farmer adaption of water quality protection practices. $\mathrm{J}$ AgricResour Econ 22(1):30-43

Food and Agriculture Organization of the United Nations (2009) Myanmar: Post-Nargis recovery and rehabilitation programme Strategy. pp.20. http://www.fao.org/resilience/resources/resources-detail/ en/c/171208/. Accessed 1 June 2020

Franzén F, Dinnétz P, Hammer M (2016) Factors affecting famers' willingness to participate in eutrophication mitigation: a case study of preferences for wetland creation in Sweden. Ecol Econ 130:8-15. https://doi.org/10.1016/j.ecolecon.2016.05.019

Geweke J (2012) Nonparametric Bayesian modelling of monotone preferences for discrete choice experiments. J Econom 171:185-204. https://doi.org/10.1016/j.jeconom.2012.06.003

Greatrex H, Hansen J, Garvin S, Diro R, Blakeley S, Le Gue M, Rao K, Osgood D (2015) Scaling up index insurance for smallholder farmers: Recent evidence and insights. CCAFS Report No.14 Copenhagen: CGIAR Research Program on Climate Change, Agriculture and Food Security (CCAFS). https://hdl.handl e.net/10568/53101. Accessed 1 June 2020

Grömping U (2018) R package DoE.base for factorial experiments. J Stat Softw 85(5):1-41. https://doi.org/10.18637/jss.v085.i05

$\mathrm{Gu}, \mathrm{Y}$ (2018) Rice production risk and demand for saline water insurance in Ayeyarwady Delta of Myanmar. Master Thesis, The University of Tokyo

Hensher DA, Greene WH (2003) The mixed logit model: the state of practice. Transportation (Amst) 30:133-176. https://doi. org/10.1023/A:1022558715350

Hensher DA, Rose JM, Greene WH (2015) Applied choice analysis, 2nd edn. Cambridge University Press, Cambridge, UK

Hess S, Palma D (2019) Apollo: a flexible, powerful and customisable freeware package for choice model estimation and application. J Choice Model 32:100170. https://doi.org/10.1016/j. jocm.2019.100170

Hess S, Palma D (2020) Apollo: a flexible, powerful and customisable freeware package for choice model estimation and application. Choice Modelling Centre. R package version 0.1.0. http://www. ApolloChoiceModelling.com/

Hollin IL, Peay HL, Bridges JFP (2015) Caregiver preferences for emerging Duchenne muscular dystrophy treatments: a comparison of best-worst scaling and conjoint analysis. Patient 8:19-27. https ://doi.org/10.1007/s40271-014-0104-X

Holmes TP, Adamowicz WL, Carlsson F (2017) Choice experiments. In: Champ PA, Boyle KJ, Brown TC (eds) A primer on nonmarket valuation. Springer, Dordrecht, pp 133-186

Hong B, Takahashi Y, Yabe M (2017) Determinants of marketability for organic biomass liquid fertilizer from human waste in Da Nang City, Vietnam. J Environ Prot 8:1354-1371. https://doi. org/10.4236/jep.2017.811083 
International Fund for Agricultural Development (2011) Weather index-based insurance in agricultural development: a technical guide. International Fund for Agricultural Development, Roma, Italy. https://www.ifad.org/en/web/knowledge/publication/asset /40239811. Accessed on 16 Sep 2020

Jaspersen JG (2016) Hypothetical surveys and experimental studies of insurance demand: a review. J Risk Insur 83:217-255. https://doi. org/10.1111/jori.12100

Jensen N, Barrett C (2017) Agricultural index insurance for development. Appl Econ Perspect Policy 39:199-219. https://doi. org/10.1093/aepp/ppw002

Johnson FR, Kanninen B, Bingham M, Özdemir S (2007) Experimental design for stated choice studies. In: Kanninen BK (ed) Valuing environmental amenities using stated choice studies. Springer, Netherlands, pp 159-202

Just A, Wellmann R, Bennewitz J (2018) Estimation of relative economic weights and the marginal willingness to pay for breeding traits of Brown Swiss cattle using discrete choice experiments. J Dairy Sci 101:5207-5213. https://doi.org/10.3168/jds.2017-14012

Kikushima R, Nakajima S, Takano M, Ito N (2018) Hong Kong consumer preferences for Japanese beef: label knowledge and reference point effects. AnimSci J 89:1519-1529. https://doi. org/10.1111/asj.13085

Kunimitsu Y (2009) Measuring the implicit value of paddy irrigation water: application of RPML model to the contingent choice experiment data in Japan. Paddy Water Environ 7(3):177-185. https://doi.org/10.1007/s10333-009-0159-9

Louviere JJ, Hensher DA, Swait JD (2000) Stated preference methods: analysis and application. Cambridge University Press, UK

Louviere JJ, Islam T (2008) A comparison of importance weights and willingness-to-pay measures derived from choice-based conjoint, constant sum scales and best-worst scaling. J Bus Res 61:903911. https://doi.org/10.1016/j.jbusres.2006.11.010

Lutta AI, Robinson LW, Wasonga OV, Ruto E, Sircely J, Nyangito MM (2020) Economic valuation of grazing management practices: discrete choice modeling in pastoral systems of Kenya. J Environ Plan Manag 63:335-351. https://doi.org/10.1080/09640 568.2019.1584097

Mahul O, Stutley CJ (2010) Government support to agricultural insurance: challenges and options for developing countries. The World Bank, Washington, D.C

Maruyama T, Takimoto H (2008) An economic evaluation of Kanazawa and Shichika irrigation water's multi-functional roles using CVM. Paddy Water Environ 6:309-318. https://doi.org/10.1007/ s10333-008-0121-2

McGurk E, Hynes S, Thorne F (2020) Participation in agri-environmental schemes: a contingent valuation study of farmers in Ireland. J Environ Manag 262:110243. https://doi.org/10.1016/j. jenvman.2020.110243

McIntosh C, Sarris A, Papadopoulos F (2013) Productivity, credit, risk, and the demand for weather index insurance in smallholder agriculture in Ethiopia. Agric Econ 44:399-417. https://doi. org/10.1111/agec.12024

Ministry of Agriculture and Irrigation (2015) Myanmar rice sector development strategy. pp 95. http://books.irri.org/MRSDS_conte nt.pdf. Accessed 1 June 2020

Miranda MJ, Farrin K (2012) Index insurance for developing countries. Appl Econ Perspect Policy 34:391-427. https://doi.org/10.1093/ aepp/pps031

Miura K, Sakurai T (2012) Who purchases weather index insurance?: results from a field experiment in rural Zambia. J Rural Econ Spec Issue 2012:442-449 (In Japanese)

Oishi T, Nakano R, Matsuno Y (2019) Perception and valuation of paddy field dam functions by rural communities: a CVM approach. Paddy Water Environ 17:383-390. https://doi. org/10.1007/s10333-019-00733-2

Perni A, Martínez-Paz JM (2017) Measuring conflicts in the management of anthropized ecosystem: evidence from a choice experiment in a human-created Mediterranean wetland. J Environ Manage 203:40-50. https://doi.org/10.1016/j.jenvman.2017.07.049

R Core Team (2020) R: a language and environment for statistical computing. R Foundation for Statistical Computing, Vienna, Austria. https://www.R-project.org/

Rakatama A, Pandit R, Iftekhar S, Ma C (2018) Heterogeneous public preference for REDD+ projects under different forest management regimes. Land Use Policy 78:266-277. https://doi.org/10.1016/j. landusepol.2018.07.004

Rao VR (2014) Applied conjoint analysis. Springer, Heidelberg

Rigby D, Alcon F, Burton M (2010) Supply uncertainty and the economic value of irrigation water. Eur Rev Agric Econ 37:97-117. https://doi.org/10.1093/erae/jbq001

Rose JM, Bliemer MCJ (2009) Constructing efficient stated choice experimental designs. Transp Rev 29:587-617. https://doi. org/10.1080/01441640902827623

Scarpa R, Rose JM (2008) Design efficiency for non-market valuation with choice modelling: how to measure it, what to report and why. Aust J AgricResour Econ 52:253-282. https://doi.org/10.11 11/j.1467-8489.2007.00436.x

Sibiko KW, Veettil PC, Qaim M (2018) Small farmers' preferences for weather index insurance: insights from Kenya. Agric Food Secur 7:53. https://doi.org/10.1186/s40066-018-0200-6

SOMPO Holdings (2019) Adaptation to climate change. https://www. sompo-hd.com/en/csr/action/community/content $4 /$. Accessed 1 June 2020

Tadesse MA, Alfnes F, Erenstein O, Holden ST (2017) Demand for a labor-based drought insurance scheme in Ethiopia: a stated choice experiment approach. Agric Econ 48:501-511. https:// doi.org/10.1111/agec.12351

Train K (2009) Discrete choice methods with simulation, 2nd edn. Cambridge University Press, NY. https://doi.org/10.1017/CBO97 80511805271

Wakamatsu H, Fukui S, Miwa K (2019) Heterogeneous preferences for micro health insurance attributes in rural Cambodia: latent class analysis. Econ Bull 39(4):2963-2975

Walker JL, Wang Y, Thorhauge M, Ben-Akiva M (2018) D-efficient or deficient? a robustness analysis of stated choice experimental designs. Theory Dec 84:215-238. https://doi.org/10.1007/s1123 8-017-9647-3

Ward PS, Makhija S (2018) New modalities for managing drought risk in rain-fed agriculture: evidence from a discrete choice experiment in Odisha, India. World Dev 107:163-175. https://doi. org/10.1016/j.worlddev.2018.03.002

World Bank (2011) Weather index insurance for agriculture: guidance for development practitioners. Agricultural and rural development discussion paper 50. World Bank Group, Washington, D.C. https ://openknowledge.worldbank.org/handle/10986/26889. Accessed on 18 Sep 2020

Wu X, Hu B, Xiong J (2020) Understanding heterogeneous consumer preferences in Chinese milk markets: a latent class approach. J Agric Econ 71:184-198. https://doi.org/10.1111/1477-9552.12327

Zuo A, Hou L, Huang Z (2020) How does farmers' current usage of crop straws influence the willingness-to-accept price to sell? Energy Econ 86:104639. https://doi.org/10.1016/j.eneco .2019 .104639 